\title{
The Role of Intact Frontostriatal Circuits in Error Processing
}

\author{
Markus Ullsperger and D. Yves von Cramon
}

\begin{abstract}
The basal ganglia have been suggested to play a key role in performance monitoring and resulting behavioral adjustments. It is assumed that the integration of prefrontal and motor cortico-striato-thalamo-cortical circuits provides contextual information to the motor anterior cingulate cortex regions to enable their function in performance monitoring. So far, direct evidence is missing, however. We addressed the involvement of frontostriatal circuits in performance monitoring by collecting event-related brain potentials (ERPs) and behavioral data in nine patients with focal basal ganglia lesions and seven patients with lateral prefrontal cortex lesions while they performed a flanker task. In both patient groups, the amplitude of the error-related
\end{abstract}

negativity was reduced, diminishing the difference to the ERPs on correct responses. Despite these electrophysiological abnormalities, most of the patients were able to correct errors. Only in lateral prefrontal cortex patients whose lesions extended into the frontal white matter, disrupting the connections to the motor anterior cingulate cortex and the striatum, were error corrections severely impaired. In sum, the frontostriato-thalamo-cortical circuits seem necessary for the generation of error-related negativity, even when brain plasticity has resulted in behavioral compensation of the damage. Thus, error-related ERPs in patients provide a sensitive measure of the integrity of the performance monitoring network.

\section{INTRODUCTION}

In a changing environment, continuous performance monitoring and subsequent behavioral adjustments are indispensable for adaptive, goal-directed behavior. For more than 10 years, researchers have focused on an event-related potential (ERP) associated with response errors, the error-related negativity (ERN) or error negativity (Ne) (Gehring, Goss, Coles, Meyer, \& Donchin, 1993; Falkenstein, Hohnsbein, Hoormann, \& Blanke, 1990). It is elicited by execution of prepotent but incorrect responses in choice reaction time tasks, peaks about 50 to $100 \mathrm{msec}$ after the erroneous response, and has a frontocentral scalp distribution. A second errorrelated ERP, the error positivity (Pe), has a centroparietal distribution and occurs about 300 to $500 \mathrm{msec}$ after the erroneous response (Falkenstein, Hoormann, Christ, \& Hohnsbein, 2000). Its functional significance is still unclear (Falkenstein, 2004); it may be related to the conscious awareness of errors (Nieuwenhuis, Ridderinkhof, Blom, Band, \& Kok, 2001).

According to current theories, the ERN reflects postresponse conflict or mismatch between the erroneous response and the competing correct response tendency (Yeung, Cohen, \& Botvinick, 2004; Coles, Scheffers, \& Holroyd, 2001). It is assumed to be generated in the

Max Planck Institute for Human Cognitive \& Brain Sciences, and the Day Clinic of Cognitive Neurology, Leipzig University

anterior cingulate cortex (ACC), specifically in the rostral cingulate zone (RCZ; Swick \& Turken, 2002; Ullsperger \& von Cramon, 2001; Dehaene, Posner, \& Tucker, 1994), the human homologue of the monkey's rostral cingulate motor area. Neuroimaging and single-unit recordings showed that this cortical area is part of a larger network signaling the need for behavioral change to optimize action outcome (Ridderinkhof, Ullsperger, Crone, \& Nieuwenhuis, 2004; Ullsperger, Volz, \& von Cramon, 2004; Williams, Bush, Rauch, Cosgrove, \& Eskandar, 2004). Evidence from nonhuman primates suggests that it receives inputs from the adjacent pre-SMA and dorsal premotor cortex as well as the thalamic ventroanterior nucleus (pars caudalis) and the oral part of the ventrolateral nucleus (Hatanaka et al., 2003). These thalamic nuclei, in turn, are sites of termination of pallidal efferents (Dum \& Strick, 1993). The RCZ projects to premotor and caudal motor areas as well as the striatum, particularly in the putamen and the striatal cell bridges (Haber, 2003; Takada et al., 2001). Furthermore, reciprocal connections of the ACC and lateral prefrontal cortex (LPFC) have been described (Petrides \& Pandya, 1999; Bates \& GoldmanRakic, 1993). In humans, the RCZ and pre-SMA are functionally connected with the LPFC (Derrfuss, Brass, \& von Cramon, 2004; Paus, Castro-Alamancos, \& Petrides, 2001; Koski \& Paus, 2000). The LPFC itself also projects to the $\mathrm{BG}$, specifically to the rostral striatum. Whereas original models suggested segregated parallel information processing cortico-striato-thalamocortical circuits 
(Alexander, Crutcher, \& DeLong, 1990), more recent views advocate an additional integrative function of the BG (Bar-Gad, Morris, \& Bergman, 2003; Haber, 2003). In particular, the structure of the BG-thalamus-cortex connections appears to "mediate information flow from higher cortical "association" areas of the prefrontal cortex to rostral motor areas" (Haber, 2003, p. 325).

These mutual connections suggest that, in addition to the RCZ, the basal ganglia (BG) and the LPFC play an important role in performance monitoring. The $\mathrm{BG}$ have been suggested to be involved in motor control, in encoding and predicting the serial order of events, and in learning-functions that are highly relevant for performance monitoring in the service of response adjustments. Several computational models have addressed how the BG mediate these functions (Bar-Gad et al., 2003; Gillies \& Arbuthnott, 2000). Relevant to learning and adaptive behavior are actor-critic models integrating knowledge about BG anatomy and physiology (Barto, 1995; Houk, Adams, \& Barto, 1995). It is assumed that the striatal patch compartments and the mesencephalic dopamine neurons form the basis of the adaptive critic (striatal patch neurons project to the mesencephalic dopamine system (Graybiel, Aosaki, Flaherty, \& Kimura, 1994; Gerfen, 1992)). According to the models, the critic learns to predict rewards from the ongoing actions and information from the environment. Any unexpected discrepancy from outcome prediction results in phasic teaching signals of the dopamine system used by the actor module to optimize behavior and by the critic to optimize prediction. The actor module has been associated with the striatal matrix compartments (Barto, 1995; Houk et al., 1995) and with the RCZ (Holroyd \& Coles, 2002). A recent functional magnetic resonance imaging study suggested partly dissociable contributions of the ventral and dorsal striatum to an actor-critic architecture, with the former corresponding to the critic and the latter to the actor (O'Doherty et al., 2004). Studies in monkeys demonstrated phasic changes in activity of the mesencephalic dopamine system signaling errors in reward prediction to the striatum as well as to the cortex (Schultz, 2002). It has been suggested that the ERN is generated when the dopaminergic teaching signal is conveyed from the midbrain to the ACC (Holroyd \& Coles, 2002). Specifically, it has been proposed that the phasic dopamine signals modulate the activity of motor neurons in the RCZ, which is measurable at the scalp as changes in ERN amplitude. Phasic decreases in dopamine activity (indicating a negative reward prediction error) are associated with large ERNs and phasic increases (indicating a positive reward prediction error) with small ERNs.

The LPFC has been shown to be involved in processes related to maintenance and updating of task representations in task preparation (Brass \& von Cramon, 2004; Derrfuss et al., 2004; MacDonald, Cohen, Stenger, \&
Carter, 2000). Thus, it may be assumed that it provides contextual information about the goals and the task at hand that is needed to predict and evaluate the events associated with an action.

In sum, the anatomical connectivity and computational models suggest that the RCZ receives inputs from the LPFC and from the BG circuits providing information on task context, ongoing events, and competing motor responses, and that these inputs are modulated by the dopamine activity in the midbrain. These considerations lead to the prediction that lesions to any of these structures-the motor striato-thalamo-cortcial circuit, LPFC, and the RCZ itself-should impair performance monitoring and resulting behavioral adjustments. In fact, unilateral lesions of the LPFC were shown to impair the generation of electrophysiological correlates of error processing (Ullsperger, von Cramon, \& Müller, 2002; Gehring \& Knight, 2000). Both studies revealed a diminished difference between ERPs on correct and incorrect trials. In the former study, this was due to increase in ERN-like responses on correct trials, whereas the latter study reported a decrement of the ERN on error trials. Moreover, results on immediate error correction in these patients were not conclusive. Studies on the role of the $\mathrm{BG}$ in error processing by investigating patients with mild to moderate Parkinson's disease did not reveal unequivocal findings. Although one study, decreased ERN amplitudes were found (Falkenstein et al., 2001), another group did not find impairments of the ERN in patients with unilateral symptoms (Holroyd, Praamstra, Plat, \& Coles, 2002). As the decrease in dopamine release may have affected the BG and the mesocortical pathway to the RCZ, interpretation is difficult.

Here we report an ERP study of error processing in nine patients with unilateral lesions of the BG and seven patients with unilateral lesions of the LPFC (Figure 1A and $\mathrm{B}$; Table 1) while they committed errors in a speeded flanker task. The BG lesions focused to the putamen and the pallidum, the latter being the output relay of the BG. Thus, the information flow in the cortico-striato-thalamo-cortical circuits could be expected to be impaired. We additionally investigated immediate corrective behavior in these patient groups by instructing them to immediately correct encountered errors by a second key press. Intentional error corrections are associated with activity in the RCZ and pre-SMA (Fiehler, Ullsperger, \& von Cramon, 2004), and lesions of the RCZ result in decrease in error correction abilities (Swick \& Turken, 2002). Moreover, corrective responses are associated with an additional negative deflection, the correction-related negativity (CoRN; Fiehler, Ullsperger, \& Von Cramon, 2005). Incidental (i.e., spontaneous, noninstructed) error corrections have been suggested to be delayed correct responses (Rabbitt, 2002). However, the instruction to correct errors leads to an increase in slow error corrections, which are likely to result from performance monitoring, 
Figure 1. Lesion overlay plots. Lesions of each individual were segmented manually and overlaid on a healthy brain template after normalization to stereotactic space. (A) Lesion overlap of all basal ganglia patients. The lesion segment of Patient 329 was flipped to the left hemisphere. Coronal $(y=-9)$, sagittal $(x=-30)$, and axial slice $(z=0)$. (B) Lesion overlap of all lateral prefrontal cortex (LPFC) patients. The lesion segment of Patient 370 was flipped to the left hemisphere. Coronal $(y=18)$, sagittal $(x=-38)$, and axial slice $(z=13)$. (C) Lesion part unique to the three LPFC patients with impaired error correction. Left: coronal $(y=10)$, sagittal $(x=-27)$, and axial $(z=$ $6,11)$ slices. Right: oblique topographical view from above and front. $\mathrm{RCZ}=$ rostral cingulate zone; $\mathrm{Cd}=$ caudate nucleus; Put $=$ putamen.
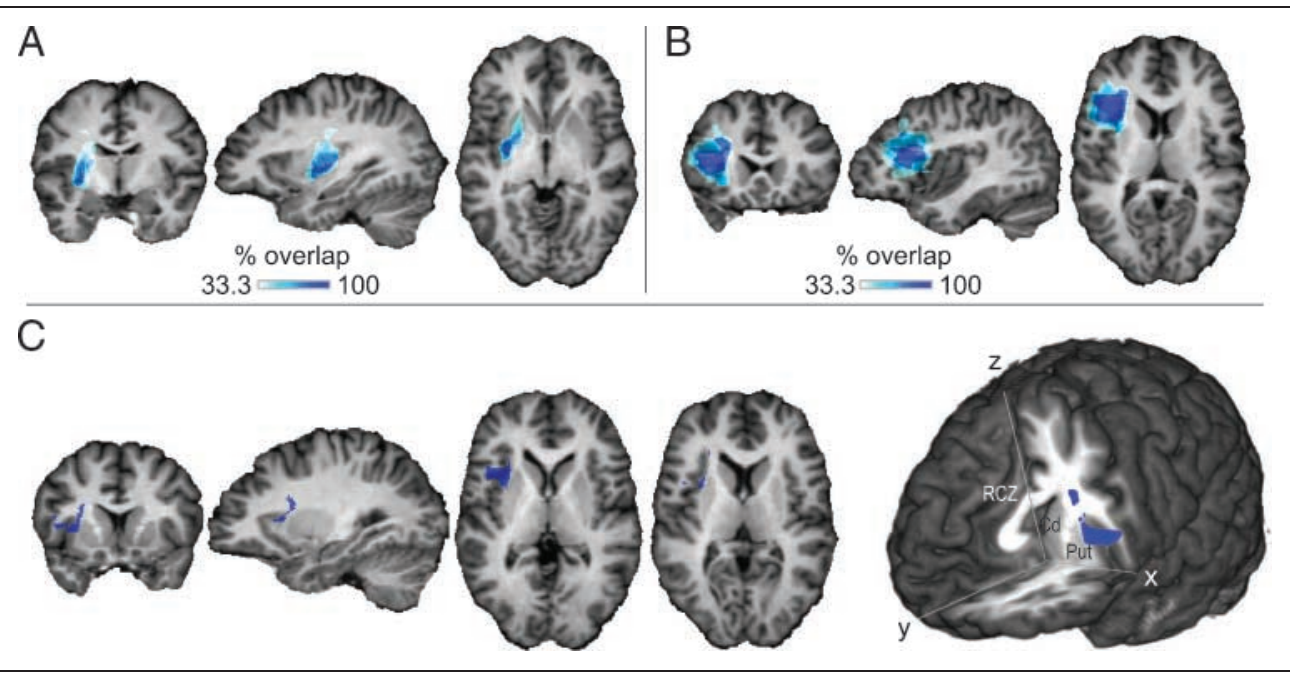

as ERP and functional imaging studies suggest (Fiehler et al., 2004, 2005).

Given the theoretical considerations about the importance of the LPFC and BG in performance monitoring, we expected impairments of the ERP correlates of error processing and of error correction.

\section{METHODS}

\section{Participants}

Two groups of patients and two control groups of healthy participants who were matched to the corresponding patient groups with respect to age and socioeconomic status participated in the study. Demographic data and lesion descriptions are shown in Table 1.

One group of nine patients (one woman) suffered from chronic unilateral lesions of the basal ganglia (BG group; mean age 49.1 years, range 29-66; mean years of education 11.3, range 10-13; mean time since lesion 3.6 years, range $1.5-5.5$ years). A lesion overlay plot is shown in Figure 1A; representative anatomical MR slices for each patient can be found in Figure 2. The corresponding control group ( $n=9$, one woman) had a mean age of 49.8 years (range 29-67) and, on average, 11.6 years of education (range 10-13).

The second group of patients consisted of seven patients (two women) with unilateral lesions of the lateral prefrontal cortex (LPFC group; mean age 54.6 years, range 41-73; mean years of education 10.9, range 8-16; mean time since lesion 5.2 years, range $2.5-7.5$ years). A lesion overlay plot is shown in Figure 1B; representa- tive anatomical MR slices for each patient can be found in Figure 2 (bottom). The corresponding control group ( $n=7$, two women) had a mean age of 54.7 years (range 40-73) and, on average, 11.0 years of education (range 10-13).

Patients as well as healthy volunteers gave written informed consent prior to participating in the study. The experiments were conducted in accordance with the Declaration of Helsinki and were approved by the ethical committee of the University of Leipzig.

\section{Procedure}

A speeded modified flanker task known to elicit the ERN and to be suitable for patient studies was used in the study (Ullsperger et al., 2002). In the task, participants were presented with a fixation mark for about $500 \mathrm{msec}$ at the center of a screen, after which four flanker arrows occurred for $110 \mathrm{msec}$. The arrows were $0.46^{\circ}$ tall and $1.08^{\circ}$ wide, and appeared $0.52^{\circ}$ and $1.04^{\circ}$ above and below the screen center. The target arrow was presented for $30 \mathrm{msec}$ in the center of the flanker arrows; its onset was delayed by $80 \mathrm{msec}$ from the flanker's onset. In $50 \%$ of trials (total trial number 480 ) the flankers pointed in the same direction as the target (compatible trial), and in the other half in the opposite direction (incompatible trial). Compatible and incompatible trials appeared in pseudorandomized order. Participants were instructed to respond with maximal speed and accuracy to the target arrow with the hand indicated by its direction. Additionally, participants were instructed to 
Table 1. Demographic Data of Patients

\begin{tabular}{|c|c|c|c|c|c|c|}
\hline $\begin{array}{l}\text { Patient } \\
\text { ID }\end{array}$ & Sex & $\begin{array}{c}\text { Age at } \\
\text { Test (years) }\end{array}$ & $\begin{array}{c}\text { Time Since } \\
\text { Lesion (years) }\end{array}$ & $\begin{array}{l}\text { Side of } \\
\text { Lesion }\end{array}$ & Etiology & Lesion Description \\
\hline \multicolumn{7}{|c|}{ Basal ganglia group } \\
\hline P157 & M & 60 & 5.5 & $\mathrm{~L}$ & MCAI & Ant. GPe, ant. IC \\
\hline $\mathrm{P} 214$ & M & 51 & 5 & $\mathrm{~L}$ & $\mathrm{ICH}$ & Post. put., GPe, post. EC, IC, lat. thal. \\
\hline P329 & M & 42 & 4.5 & $\mathrm{R}$ & $\mathrm{ICH}$ & Post. put. post. EC \\
\hline P353 & M & 46 & 4 & $\mathrm{~L}$ & $\mathrm{ICH}$ & Put., GPe, EC, ant. IC, reduced volume of caud. \\
\hline P364 & M & 29 & 3.5 & $\mathrm{~L}$ & MCAI & $\begin{array}{l}\text { Post. put., caud. (body), middle ins., } \\
\text { parietal operculum }\end{array}$ \\
\hline $\mathrm{P} 438$ & M & 52 & 3 & $\mathrm{~L}$ & LI & GPi, polar thal., IC (knee) \\
\hline P536 & M & 66 & 2.5 & $\mathrm{~L}$ & MCAI & $\begin{array}{l}\text { Caud. (ant. body), ant. put., GPe, EC, ant. IC, } \\
\text { ant. ins., preinsular WM }\end{array}$ \\
\hline P723 & $\mathrm{F}$ & 38 & 1.5 & $\mathrm{~L}$ & MCAI & $\begin{array}{l}\text { Caud. (body), put., GPe, ant. IC, EC, } \\
\text { parietal operculum, post. ins. }\end{array}$ \\
\hline P621 & M & 58 & 3 & $\mathrm{~L}$ & MCAI & Caud. (body), put., GPe, IC, EC \\
\hline
\end{tabular}

Lateral prefrontal cortex group

\begin{tabular}{lllllll} 
P009 & F & 60 & 7.5 & L & MCAI & LPFC, ant. ins., preinsular WM, ant. put. \\
P102 & M & 53 & 7 & L & MCAI & LPFC, ant. ins., preinsular WM, ant. put. \\
P237 & M & 63 & 5 & L & MCAI & LPFC, ant. ins., preinsular WM \\
P325 & M & 42 & 5 & L & AVM & LPFC, ant. ins. \\
P369 & F & 50 & 4 & L & MCAI & LPFC, ant. Ins. \\
P370 & M & 41 & 5.5 & R & TBI & LPFC, ant. lat. temporal \\
P403 & M & 73 & 2.5 & L & MCAI & LPFC \\
\hline
\end{tabular}

$\mathrm{M}=$ male; $\mathrm{F}=$ female $\mathrm{L}=$ left $\mathrm{R}=$ right; $\mathrm{MCAI}=$ middle cerebral artery infarct (involving striolenticular arteries); $\mathrm{ICH}=$ intracerebral hemorrhage; $\mathrm{LI}=$ lacunar infarcts; $\mathrm{AVM}=$ arteriovenous malformation; $\mathrm{TBI}=$ traumatic brain injury; ant. = anterior; post. = posterior; caud. = caudate nucleus; $\mathrm{EC}=$ external capsule system; $\mathrm{IC}=$ internal capsule; ins. $=$ insula; $\mathrm{GPe}=$ globus pallidus externus; $\mathrm{GPi}=$ globus pallidus internus; $\mathrm{LPFC}=$ lateral prefrontal cortex; put. = putamen; thal. $=$ thalamus; $\mathrm{WM}=$ white matter.

correct errors whenever they noticed one. At $1400 \mathrm{msec}$ after target onset, each response was followed by a symbolic feedback (600 msec) informing participants whether their answer was fast enough or should be speeded up. After the feedback, a fixation cross was presented for $500 \mathrm{msec}$, such that the intertrial interval amounted to $2580 \mathrm{msec}$.

We introduced an adaptive algorithm, which dynamically adjusted the response time pressure based on the participant's performance (Fiehler et al., 2005). The algorithm aimed at an optimization of error rate (goal: $20 \%$ incompatible errors) and a minimization of late response rates. This procedure helped to reduce dropouts for a low number of error trials.

\section{Electrophysiological Recordings}

The participants were seated comfortably in a dimly lit, electrically shielded chamber. The electroencephalo- gram (EEG) was recorded with $\mathrm{Ag} / \mathrm{AgCl}$ electrodes from 28 electrode sites (FP1, FP2, F7, F3, Fz, F4, F8, FT7, FCz, FT8, T7, C3, Cz, C4, T8, CP5, CP6, P7, P3, Pz, P4, P8, O1, $\mathrm{O} 2, \mathrm{~A} 2$, ) referenced to the left mastoid and off-line rereferenced to linked mastoids. Electrode impedance was kept below $5 \mathrm{k} \Omega$. The vertical electrooculogram (EOG) was recorded from electrodes placed above and below the right eye. To monitor horizontal eye movements, the EOG was collected from electrodes placed on the outer canthus of the left and right eye. EEG and EOG were recorded continuously with a low-pass filter of $70 \mathrm{~Hz}$ and $\mathrm{AD}$ converted with 22-bit resolution at a sampling rate of $250 \mathrm{~Hz}$. First, the EEG epochs were scanned for muscular and large EOG artifacts. Whenever the standard deviation in a 200-msec interval exceeded $50 \mu \mathrm{V}$, the epoch was rejected. Next, small horizontal and vertical EOG artifacts that were still present in the EEG signal were corrected by an eye movement correction procedure based on a linear 


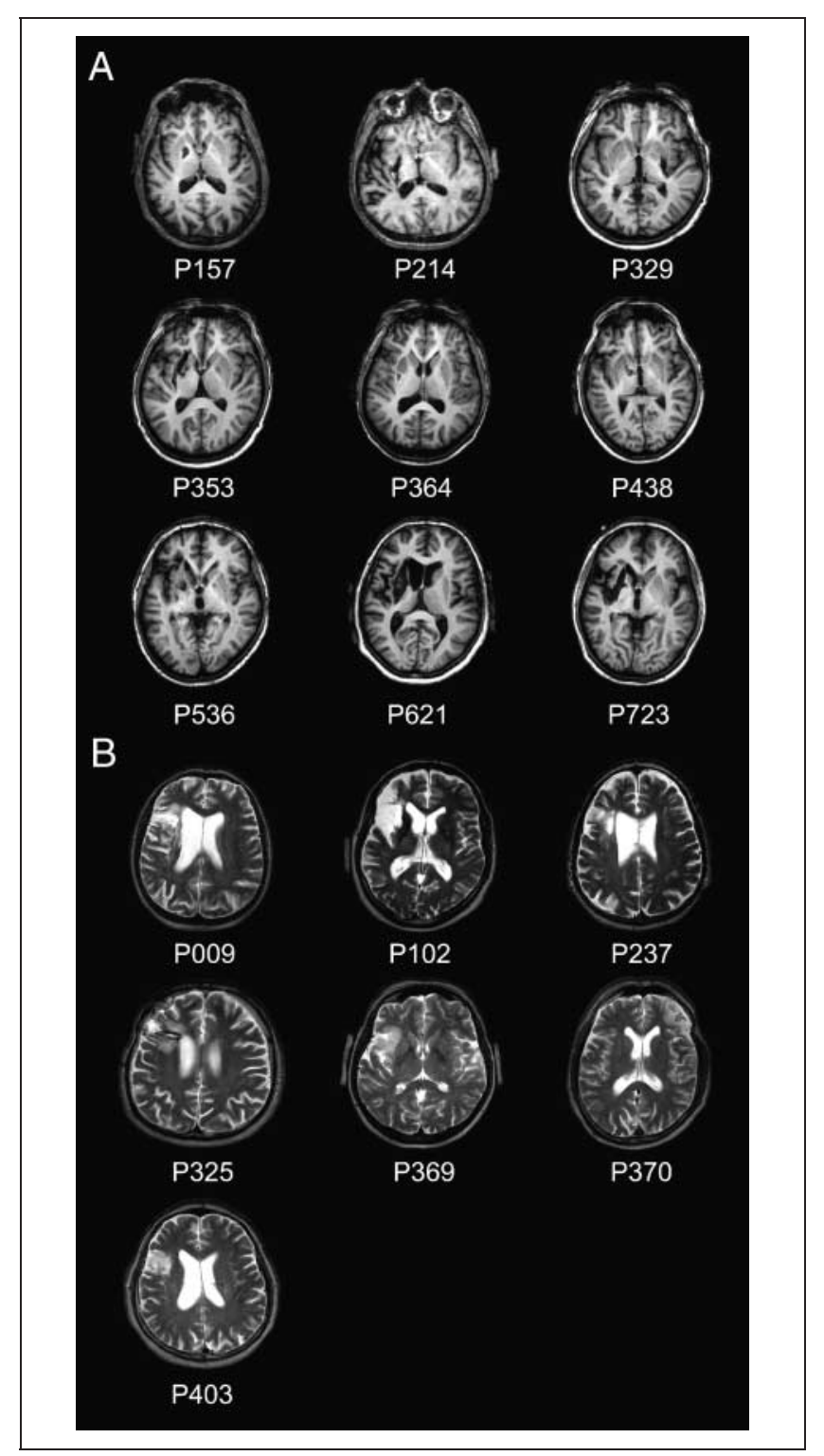

Figure 2. Representative anatomical MR slices of each patient. Anatomical convention. (A) Basal ganglia lesions, (B) lateral prefrontal cortex lesions.

regression method described by Gratton, Coles, and Donchin (1983).

\section{Data Analysis}

The time difference between target onset and button press was defined as response time. When an error was corrected by a second button press, the time difference between first (erroneous) and second (corrective) response was defined as correction time. Responses were analyzed when they occurred within 2000 msec after target onset.

Response-locked ERP epochs were averaged separately for incompatible correct and incompatible erro- neous trials starting $100 \mathrm{msec}$ before the response and continuing $500 \mathrm{msec}$ after the response. Compatible trials were excluded from ERP analyses because of an insufficient number of error trials $(<1 \%)$, as were responses delivered after the response deadline. The average voltage in the $100 \mathrm{msec}$ preceding the onset of the flanker arrows served as baseline.

For the quantification of the ERN, peak-to-peak measurements were calculated to determine baselineindependent amplitudes of negative deflections by subtracting the amplitude of the preceding positive peak from the negative peak of this component (Falkenstein, Hoormann, et al., 2000). Based on the literature, time search windows of the ERN were chosen a priori: Two early time windows were defined from -100 to 0 msec for the positive peak preceding the ERN and from 0 to 120 msec for the ERN component. The negative peak for the ERN was also used to determine its latency. Because the $\mathrm{Pe}$ is a more sustained positive deflection, peak search was not possible in many participants' data. Therefore, the mean amplitude in two time windows covering the early (120-300 $\mathrm{msec}$ ) and the late parts (300-500 msec) of this deflection were chosen (van Veen \& Carter, 2002). The early Pe time window would also cover the time range of the CoRN. For better readability, the results are reported for the ERN time window, the CoRN time window, and the late Pe time window.

Statistical effects were determined at representative electrodes at the electrodes that spanned the region where the ERN and Pe are largest (F3, FCz, F4, C3, Cz, $\mathrm{C} 4, \mathrm{P} 3, \mathrm{Pz}, \mathrm{P} 4)$. For the two patients with right-sided lesions, lateral electrodes were switched such that F3, C3, and P3 corresponded to the side ipsilateral to the lesion (Gehring \& Knight, 2000). All effects with more than one degree of freedom in the numerator were adjusted for violations of sphericity according to the formula of Huynh and Feld (1970). To avoid reporting large amounts of statistical results not relevant for the issues under investigation, only main effects or interactions, including the factors Response Type (correct, incorrect) and Group (BG, controls; LPFC, controls), are reported here. Topographical scalp potential maps were generated using a two-dimensional spherical spline interpolation and a radial projection from $\mathrm{Cz}$, which respects the length of the median arcs. For graphical display, a low-pass filter with a cutoff frequency of $15 \mathrm{~Hz}$ was applied.

Results are listed as mean \pm standard error of the mean, unless otherwise specified.

\section{Lesion Data Analysis}

The lesions of the patients were segmented manually based on high-resolution 3-D T1-weighted anatomical MR data sets. These volume data sets were aligned and normalized to standard stereotactic space (Talairach and 
Tournoux, 1988) by affine transformation. The rotational and translational parameters were subsequently used to transform lesion segments using trilinear interpolation, such that the resulting segments were aligned with the stereotactic coordinate system. Data sets for patients with lesions in the right hemisphere $(329,370)$ were flipped to allow lesion overlap analyses. For visualization purposes, the lesion data of the patients were overlapped for each patient group to form density maps (Figure 1C) (Rorden \& Karnath, 2004). In order to extract the lesion parts unique to the three LPFC patients whose error correction abilities were impaired, a stepwise masking and overlapping procedure was used. First, for each of the three patients the lesion part exceeding the union (conjunction) of the lesions of the four LPFC patients with intact error correction was determined by masking. Second, the region of intersection (i.e., region of maximal overlap) of the resulting subtraction maps was determined. The formula for this procedure is as follows:

$$
(009 \mathrm{~m} \mathrm{U}) \cap(102 \mathrm{~m} \mathrm{U}) \cap(237 \mathrm{~m} \mathrm{U}),
$$

where $\mathrm{U}$ is the lesion union of the four remaining LPFC patients ( $\mathrm{U}=325 \cup 369 \cup 370 \cup 403)$, and $\mathrm{m}$ stands for "masked by."

\section{RESULTS}

\section{Basal Ganglia Group}

\section{Behavioral Data}

Response times and error rates obtained in the BG group and their controls are shown in Table 2. Both patients and controls show compatibility effects typical for flanker tasks, that is, longer response times and higher error rates for incompatible trials than for compatible trials. This was confirmed by repeated measures analyses of variance (ANOVAs) with the within-subject factor Compatibility (two levels) and the betweensubjects factor Group (two levels), revealing a main effect of Compatibility: response times, $F(1,16)=$ $344.6, p<.0001$; error rates, $F(1,16)=94.4, p<.0001$. For response times, also a main effect of Group was observed, $F(1,16)=8.4, p<.05$, reflecting that $\mathrm{BG}$ patients responded more slowly. This is also reflected in the increase in mean response deadline for the patients, $616 \pm 38$ vs. $484 \pm 18 \mathrm{msec} ; t(16)=3.08$, $p<.01$. The rate of incompatible errors committed before the deadline did not differ significantly between groups (patients $14.2 \pm 1.8 \%$ vs. controls $11.3 \pm 1.8 \%$, $p>$.28). For incompatible trials, response times were shorter for errors than for correct responses in both groups (Table 2). An ANOVA with the factors Response

Table 2. Mean Proportions and Reaction Times of Correct and Erroneous Responses in Patients and Controls Broken Down by Compatibility

\begin{tabular}{|c|c|c|c|}
\hline \multicolumn{2}{|c|}{ Compatible Trials } & \multicolumn{2}{|c|}{ Incompatible Trials } \\
\hline Response & Response & Response & Response \\
\hline Rates (\%) & Times (msec) & Rates (\%) & Times (msec) \\
\hline
\end{tabular}

Basal ganglia group

$\begin{array}{lcccc}\text { Correct } & 94.7(1.4) & 451.8(25.7) & 83.1(2.4) & 547.7(23.5) \\ \text { Erroneous } & 3.5(1.0) & - & 15.1(2.1) & 440.8(20.3)\end{array}$

Control group for basal ganglia patients

$\begin{array}{lcccc}\text { Correct } & 99.0(0.4) & 370.0(12.1) & 88.1(2.0) & 468.2(15.5) \\ \text { Erroneous } & 0.5(0.2) & - & 11.5(1.9) & 419.2(26.2)\end{array}$

Lateral prefrontal cortex group

\begin{tabular}{lcccc} 
Correct & $86.7(9.5)$ & $490.8(37.9)$ & $76.3(8.6)$ & $581.0(38.5)$ \\
Erroneous & $8.2(6.6)$ & - & $18.2(6.5)$ & $509.1(46.7)$ \\
& & & & \\
Control group for lateral prefrontal cortex patients & & & \\
Correct & $98.2(0.5)$ & $379.4(12.0)$ & $15.9(1.8)$ & $481.3(14.4)$ \\
Erroneous & $1.1(0.4)$ & - & $387.5(28.5)$ \\
\hline
\end{tabular}

Responses recorded before and after the response deadline were collapsed. Standard errors of the means are shown in parentheses. In most participants, the number of compatible errors was insufficient to obtain reliable response times for this condition. 
and Group revealed a main effect of Response, $F(1,16) \mathrm{L}=45.0, p<.0001$, and a Response $\times$ Group interaction, $F(1,16)=6.2, p<.05$. This interaction was elucidated by Tukey tests showing that error response times did not differ significantly, whereas response times for correct responses were prolonged in the patients. In other words, relative to correct responses the errors were more premature in the $\mathrm{BG}$ patients than in the control group (response time difference, incompatible correct - incompatible error; $107 \pm 19$ vs. $49 \pm 13$ msec, patients vs. controls).

The rate of immediate error corrections in BG patients $(81.7 \pm 10.6 \%)$ and the control group (75.1 \pm $12.4 \%)$ did not differ significantly $(p>.71)$. Correction times (the time difference of the corrective response relative to the erroneous response) were not significantly different between groups (391 \pm 48 vs. $412 \pm$ 67 msec, patients vs. controls; $p>.8)$.

To test for post-error effects, error rates and response times were submitted to ANOVAs with the factors Compatibility (two levels), Previous response type (two levels), and Group. However, neither a significant main effect of Previous response type nor an interaction with this factor was found $(p s>.24)$. This may be a result of the time pressure and is consistent with previous studies in which post-error slowing was unstable for speeded flanker tasks (Ullsperger \& von Cramon, 2004; Ullsperger et al., 2002). Moreover, it seems conceivable that post-error slowing effects are disturbed by the presence of timing feedback on every trial.

\section{ERP Data}

Figure 3 depicts the response-locked mean ERPs for hits and errors in the BG group and their corresponding controls at two midline electrodes. The waveform for the control group shows a clear ERN at FCz, followed by a CoRN, peaking around $230 \mathrm{msec}$, and a more posteriorly located Pe reaching its maximum between 300 and 500 msec. In contrast, in the patients no clear difference between the waveforms is visible in the early time window in which an ERN would be expected. Between
Figure 3. Response-locked grand average ERPs at two midline electrodes for the basal ganglia patients and the corresponding control group for correct (dashed lines) and incorrect (solid lines) responses on incompatible trials. Top: topographical distributions of the ERP difference between incorrect and correct trials in the time window 40-80 msec (i.e., time at which ERN is expected). $\mathrm{BG}=$ basal ganglia; $\mathrm{ERN}=$ error-related negativity; CoRN $=$ correction-related negativity; $\mathrm{Pe}=$ error positivity; EOGH = horizontal electrooculogram; EOGV = vertical electrooculogram.

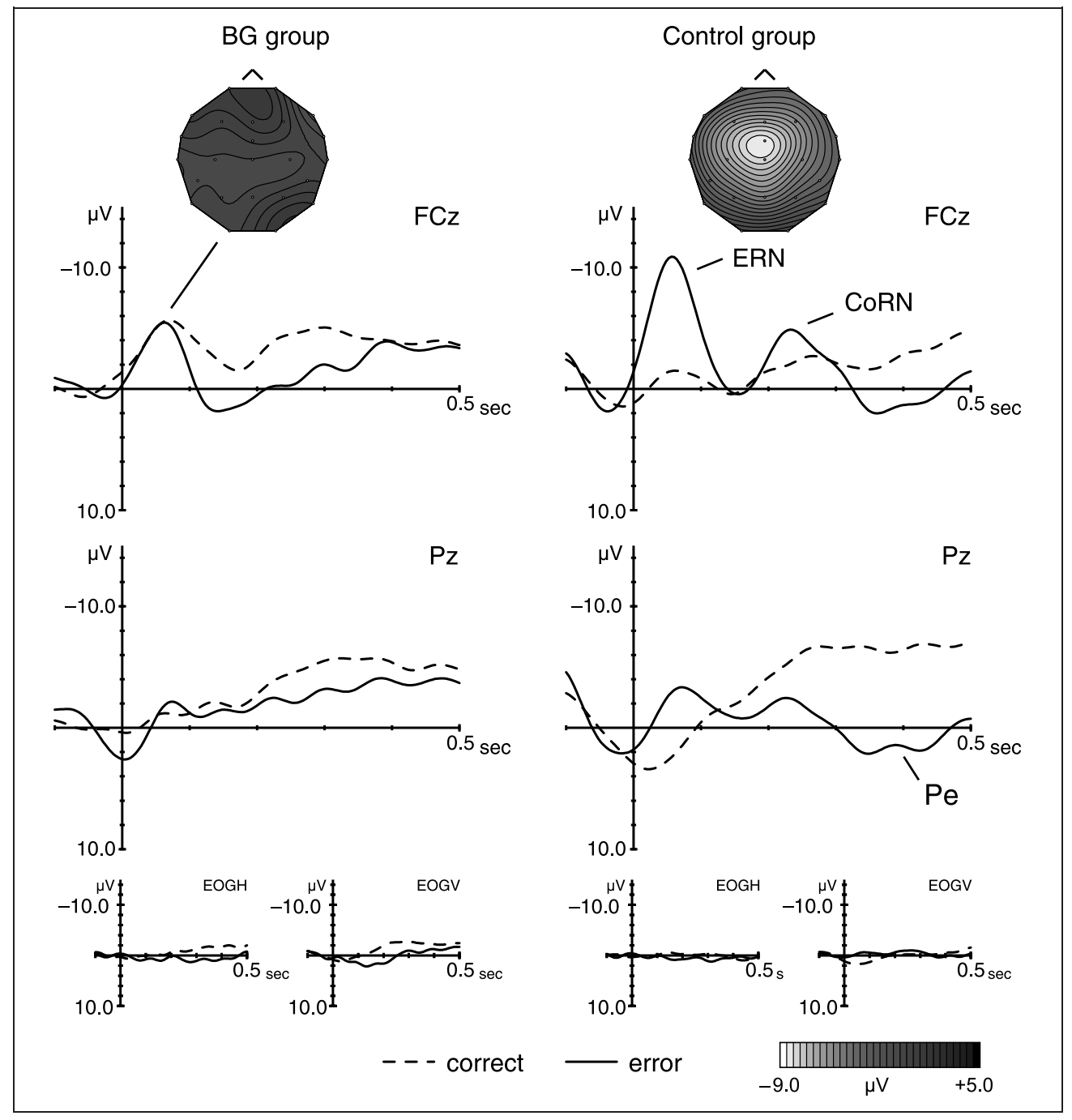


100 and $400 \mathrm{msec}$, the waveforms for incorrect responses seem to be more positive-going at frontal electrodes than for correct responses, and no CoRN is visible. Moreover, at parietal electrodes, no Pe is seen in the patients.

To test these observations, the peak-to-peak amplitude data of the ERN time window for correct and incorrect responses were submitted to a repeated measures ANOVA with the between-subjects factor Group (two levels; patients, controls) and the within-subjects factors Response (two levels; correct, incorrect), Anterior-Posterior Dimension (three levels; anterior, central, posterior sites) and Lateral Dimension (three levels; left, midline, right sites), revealing a main effect of Response, $F(1,16)=17.58, p<.001$, and a significant Response $\times$ Group interaction, $F(1,16)=7.12, p<.05$. Moreover, the interactions Response $\times$ Lateral Dimension, $F(2,32)=5.01, p<.05$, and Response $\times$ Group $\times$ Lateral Dimension, $F(2,32)=3.45, p<.05$, were significant. ${ }^{1}$ A subordinate ANOVA for correct responses revealed neither main effects, $F(1,16)=0.63$, nor interactions of the factor Group, $F(2,32)<1.24$, whereas the same ANOVA for errors gave rise to a main effect of Group, $F(1,16)=5.56, p<.05$, and a tendency for a Group $\times$ Lateral Dimension interaction, $F(2,32)=2.71$, $p=.082$. In the BG group, no effect of Response was found, $F(1,16)=3.36, p>.11$, but an interaction of Response $\times$ Anterior-Posterior Dimension, $F(2,32)=$ $4.68, p<.05$. Interestingly, a follow-up ANOVA revealed no effects of Response at anterior and central electrodes where the ERN would be expected, but a significant main effect of Response at posterior electrodes, $F(1,8)=7.94$, $p<.05$. In contrast, in the healthy controls a main effect of Response, $F(1,16)=13.56, p<.01$, and a Response $\times$ Lateral Dimension interaction, $F(1,16)=5.21, p<.05$, was found. This confirms that in the BG group the ERN amplitude was greatly reduced and the topography was changed such that at frontal electrodes the ERPs did not differ between correct and erroneous responses.

The latency of the ERN at FCz did not differ significantly between groups $(t(16)=-0.23, p>.82)$.

In the CoRN time window, the four-way ANOVA revealed the significant interactions Response $\times$ Group $\times$ Anterior-Posterior Dimension, $F(2,32)=$ $6.60, p<.05$, and Response $\times$ Lateral dimension, $F(2,32)=5.46, p<.05$. A subordinate ANOVA for incorrect trials revealed a nearly significant Group $\times$ Anterior-Posterior Dimension interaction, $F(2,32)=$ 2.94, $p<.087$. Although the weak statistical power precludes firm conclusions, this pattern of results suggests that the BG patients did not show a CoRN on errors although they corrected errors as efficiently as the controls. Instead they showed a frontal positivity on error trials as previously observed (van Veen \& Carter, 2002), reflected in a Response $\times$ Anterior-Posterior Dimension interaction in an ANOVA restricted to the patients, $F(2,16)=4.71, p<.05$.
In the late Pe time window, the four-way ANOVA revealed a main effect of Response, $F(1,16)=4.58$, $p<.05$, a significant Response $\times$ Lateral Dimension interaction, $F(2,32)=4.51, p<.05$, and a nearly significant Group $\times$ Response $\times$ Anterior-Posterior Dimension triple interaction, $F(2,32)=2.71, p<.10$. Groupwise ANOVAs revealed no significant effects or interactions of Response for the BG group ( $F_{S}<1.03$, $p s>35)$, whereas a significant Response $\times$ Lateral Dimension interaction, $F(2,32)=4.31, p<.05$, was found for the control group. These findings confirm that in contrast to the controls, the BG patients had no Pe.

Visually evoked potentials. To test whether BG lesions have a general detrimental effect on ERPs we investigated the visually evoked N1 on stimulus presentation in compatible correct trials (Figure 4, left). To this end, the amplitudes of the most negative peak between 50 and 100 msec after target onset (note that the visually more salient onset of the flankers preceded the target by 80 msec) were compared between groups. Neither the ANOVA including the representative electrodes used for the analyses above nor $t$ tests at occipital electrodes revealed group differences $(p s>.47)$.

\section{Lateral Prefrontal Cortex Group}

\section{Behavioral Data}

Response times and error rates obtained in the LPFC group and their controls are shown in the lower part of Table 2. Again, both patients and controls showed typical compatibility effects. This was confirmed by repeated measures ANOVAs with the factors Compatibility and Group, revealing a main effect of Compatibility: response times, $F(1,12)=70.3, p<.0001$; error rates, $F(1,12)=13.5, p<.01$. For response times, also a main effect of Group was observed, $F(1,16)=7.4$, $p<.05$, reflecting that LPFC patients responded more slowly. This is also reflected in tendentially increased response deadlines in the patients, $742.6 \pm 107$ vs. $520 \pm$ 18 msec; $t(16)=2.04, p=.083$. The rate of incompatible errors committed before the deadline did not differ significantly between groups (17.6 \pm 6.5\% vs. $15.4 \pm$ $1.8 \%$, patients vs. controls; $p>.74)$.

For incompatible trials, response times were shorter for errors than for correct responses in both groups. An ANOVA with the factors Response and Group revealed a main effect of Response, $F(1,12)=21.7, p<.001$. There was no interaction with Group. The main effect of Group, $F(1,12)=6.0, p<.05$, reflects that both incorrect as well as correct responses were delayed in the patients as compared to the control group.

The rate of immediate error corrections was reduced in the patients $(59.6 \pm 14.8 \%)$ vs. in the controls $(88.7 \pm$ $3.1 \%)$. This effect was marginally significant, $t(12)=$ $1.93, p=.078$. Correction time was longer in patients 
$(719 \pm 210 \mathrm{msec} ;$ median $=533 \mathrm{msec})$ than in the controls $(327 \pm 32 \mathrm{msec}$; median $=315)$; due to high variance in the patient group, this effect only approached significance, $t(12)=1.85, p=.089$. Further investigation revealed that three patients (P009, P102, P237) showed less than $30 \%$ (mean 19.6\%) immediate error corrections, whereas the other patients corrected $89.6 \%$ (similar to controls). Patients with impaired error correction did not differ from the other LPFC patients with respect to error rates $(17.8 \%$ errors on incompatible trials). Response times were prolonged (incompatible correct, $641 \mathrm{msec}$; incompatible error, $572 \mathrm{msec}$ ). Similarly, patients with impaired error correction had a mean error correction time of $1091 \mathrm{msec}$ (note that only few error corrections occurred, thus weakening reliability of this data point). Patients with normal error correction needed, on average, $417 \mathrm{msec}$ to correct errors.

We tested for post-error effects by submitting error rates and response times to ANOVAs with the factors Compatibility, Previous Response Type, and Group. Neither a significant main effect of Previous Response Type nor an interaction with this factor was found for the accuracy data $(p s>.27)$. In the response time data, a main effect of Previous Response Type, $F(1,12)=$ 23.17, $p<.001$, but no interaction with Group was found, suggesting comparable post-error slowing in both groups.

\section{ERP Data}

Figure 5 depicts the response-locked mean ERPs for correct and erroneous responses in the LPFC group and their controls at two midline electrodes. Again, the waveform for the control group shows a clear ERN at $\mathrm{FCz}$, followed by a CoRN and a more posteriorly located Pe reaching its maximum between 300 and 400 msec. In contrast, in the patients no clear difference between the waveforms is visible in the early time window in which an ERN would be expected. Between 100 and $300 \mathrm{msec}$, the waveforms for incorrect responses seem to be more positive-going at frontal electrodes, but neither a CoRN at FCz nor a Pe at Pz are seen.

To test these observations, amplitude data of the ERN time window were submitted to a four-way repeated measures ANOVA with the factors Group, Response, Anterior-Posterior Dimension, and Lateral Dimension, revealing a significant Response $\times$ Group interaction, $F(1,12)=5.13, p<.05$. Moreover, the main effect of Response approached significance, $F(1,12)=3.76$, $p<.076$. A subordinate ANOVA for correct responses revealed no significant main effects, $F(1,12)=0.02, p>.9$, or interactions of the factor Group, $F(2,24)<1.08$, $p s>$ .34, whereas the same ANOVA for errors gave rise to a main effect of Group, $F(1,12)=7.58, p<.05$, and a Group $\times$ Lateral Dimension interaction, $F(2,24)=7.18$, $p<.01$. In the LPFC group, neither a main effect of Response was found, $F(1,6)=0.32, p>.59$, nor an interaction with this factor, $F_{\mathrm{S}}(2,12)<1.54, p>.25$. In contrast, in the healthy controls a main effect of Response, $F(1,6)=6.18, p<.05$, was found. This confirms that in the LPFC group the amplitudes of the ERN are greatly reduced such that the ERPs did not differ between correct and erroneous responses in the early time window.

The latency of the ERN at FCz did not differ significantly between groups, $t(12)=-0.3, p>.7$.

In the CoRN time window, the four-way ANOVA revealed a significant main effect of Response, $F(1,12)=$ 5.84, $p<.05$. The interaction Group $\times$ Response $\times$ Lateral Dimension approached significance, $F(2,24)=$ $2.81, p<.08$. A subordinate ANOVA for errors revealed a significant Group $\times$ Lateral Dimension interaction, $F(2$, $24)=5.21, p<.05$, suggesting that the LPFC patients
Figure 4. Stimulus-locked visually evoked potentials for patients (dashed lines) and controls (solid lines). (Left) basal ganglia (BG) group; (Right) lateral prefrontal cortex (LPFC) group.

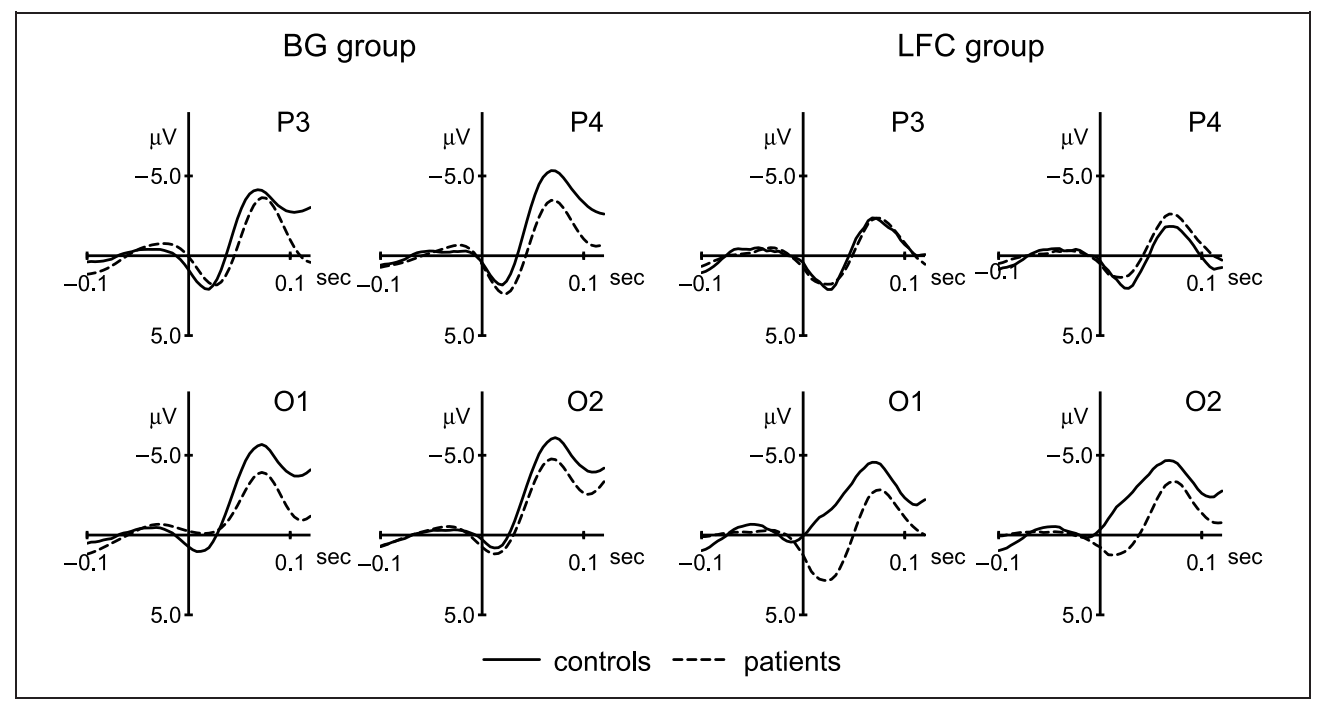


Figure 5. Response-locked grand average ERPs at two midline electrodes for the LPFC patients and the corresponding control group for correct (dashed lines) and incorrect (solid lines) responses on incompatible trials. Top: topographical distributions of the ERP difference between incorrect and correct trials in the time window 40-80 msec (i.e., time at which ERN is expected). LPFC $=$ lateral prefrontal cortex; ERN = error-related negativity; CoRN $=$ correctionrelated negativity; $\mathrm{Pe}=$ error positivity; EOGH $=$ horizontal electrooculogram; EOGV = vertical electrooculogram.

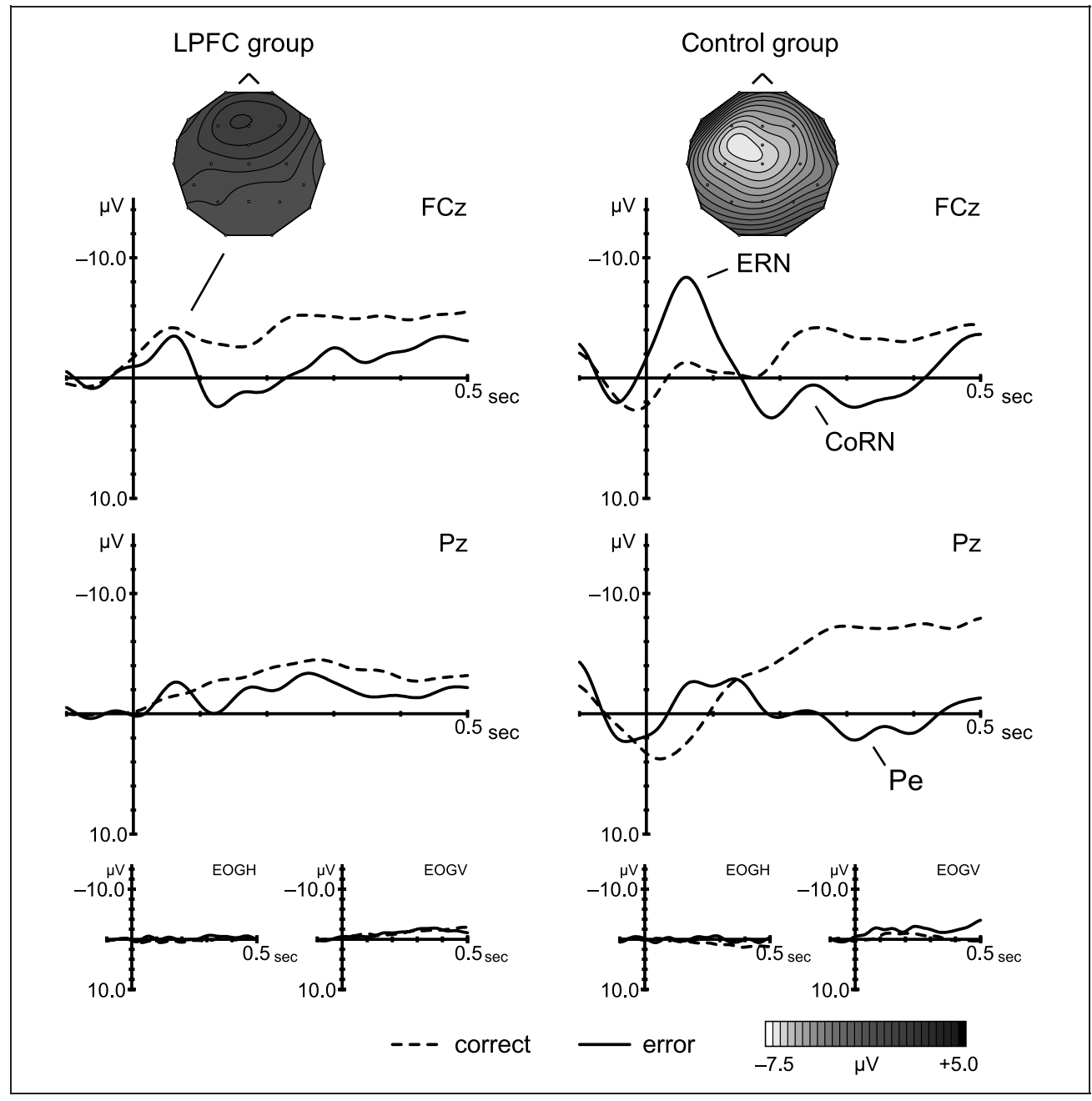

did not show a CoRN. Similarly to the BG patients, they showed a positivity on error trials, reflected in a nearly significant main effect of Response, $F(1,6), p<.099$.

In the late Pe time window, the four-way ANOVA revealed a main effect of Response, $F(1,12)=9.87$, $p<.01$, and a tendency for a Group $\times$ Response interaction, $F(1,12)=3.18, p<.099$. Groupwise ANOVAs revealed no significant effects or interactions of Response for the LPFC group $(F \mathrm{~s}<1.28, p s>.30)$, whereas a main effect of Response, $F(1,6)=9.48, p<.05$, and a Response $\times$ Lateral Dimension interaction, $F(2,12)=$ $4.43, p<.05$, were found for the control group. These findings confirm that the LPFC patients had no Pe.

In order to explore the ERP data for differences related to impairments in error correction, we performed a subgroup analysis (Figure 6). Interestingly, the general ERP pattern of the three patients with impaired error correction was quite similar to that of the other LPFC patients.

Visually evoked potentials. Similarly to the BG patients, for the LPFC group, neither the ANOVA including the representative electrodes used for the analyses above nor $t$ tests at occipital electrodes revealed group differences in the visually evoked N1 ( $p s>$.54; Figure 4, right). It should be noted that previous studies using lateralized target presentations in patients with lateral frontal lesions revealed reductions of early visually evoked potentials ipsilateral to the lesions (Barcelo, Suwazono, \& Knight, 2000). The fact that in the present study stimuli were presented centrally might explain why no reduction of the visually evoked N1 was found.

\section{DISCUSSION}

To investigate the role of the $B G$ and the LPFC in performance monitoring, we examined the ERP correlates of error processing as well as immediate corrective behavior in patients with focal lesions in these structures. Both patients with BG lesions and patients with LPFC lesions show an impaired ERN, which is greatly reduced and distorted or even absent. The centroparietal Pe and the CoRN are also absent, whereas a more frontal positivity on errors seems to be preserved in the patients. A further observation is that the ERN-like negativity on correct responses (sometimes called cor- 
Figure 6. Response-locked grand average ERPs at two midline electrodes for the LPFC patients with unimpaired (left) and impaired (right) error corrections. The general pattern is similar for both groups; visual inspection suggests that the error-related frontal positive-going effect is more pronounced in the correction-unimpaired group. LPFC $=$ lateral prefrontal cortex; EOGH = horizontal electrooculogram; EOGV = vertical electrooculogram.

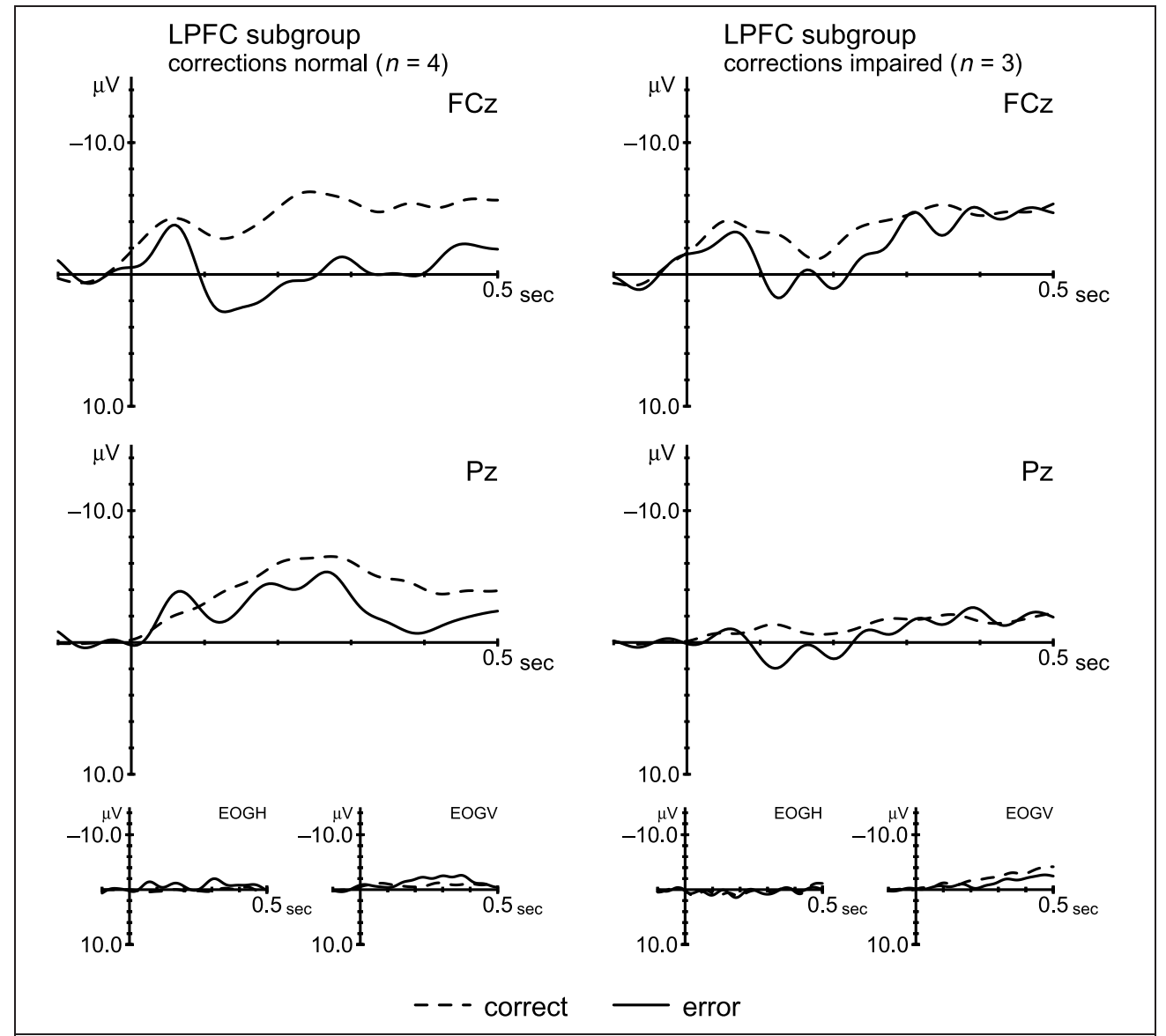

rect-related negativity; Vidal, Burle, Bonnet, Grapperon, \& Hasbroucq, 2003; Ford, 1999) is preserved if not enhanced in both patient groups, suggesting that this negativity is likely generated by a partly different network than the ERN and may reflect a different function, such as persisting uncertainty regarding the optimal response strategy (Bartholow et al., 2005). Notably, these changes in error-related ERPs are unlikely to result from a lesion effect on ERPs in general, as the visually evoked potentials are unimpaired in the patient groups. Moreover, preserved target P300 and N400 components were demonstrated for patient groups with comparable lesion patterns in the BG (Friederici, Kotz, Werheid, Hein, \& von Cramon, 2003; Frisch, Kotz, von Cramon, \& Friederici, 2003) and LPFC (Knight \& Scabini, 1998; Yamaguchi \& Knight, 1991).

Thus, ERP findings suggest that the lesions disturbed and prolonged performance monitoring processes. In both patient groups, the cortico-striato-thalamocortical loops via the pallidum and ventrolateral thalamus are damaged. Thus, the integration of contextual information about the task, the predicted serial order of events, and motor activity may be disturbed or mistimed. The notion that the pallidal inputs to the RCZ via the thalamus are necessary for the generation of the ERN is supported by the finding that thalamic lesions abol- ished the ERN (Stemmer \& Witzke, 2003). Second, the ongoing assessment of whether an event is better or worse than expected may be less exactly timed than in healthy persons, such that the proposed dopaminergic error signal is desynchronized. If this signal to the RCZ is weaker and/or scattered over time, the response at the RCZ neurons will be less synchronized such that the summation and propagation of electrical activity will result in abnormal ERPs. A hint that motor-related activity is less well synchronized in patients is provided by the findings that, in the BG group, within-subject reaction time variance is significantly larger than in controls $(p<.05)$. In the LPFC group, this effect was also present numerically but only approached significance $(p=.1)$.

However, in most patients, particularly those with lesions confined to the BG or to the LPFC, immediate error correction was unimpaired, although the ERP data suggest an impairment of the performance monitoring system. How to reconcile this apparent paradox? It has been suggested that incidental error corrections may reflect a delayed correct response that is delivered independently of error processing (Rabbitt, 2002). These incidental (spontaneous) error corrections occur in about 20-40\% of errors (Fiehler et al., 2004, 2005). However, the intention to correct errors increases the 
number of slow corrections assumed to depend on error processing and involving the RCZ. The correction rates found for the patients and controls are comparable to those reported previously for studies on intentional error corrections (above 80\%; Fiehler et al., 2004, 2005), suggesting that most patients were able to intentionally correct errors. Furthermore, it could be argued that the ERN may be an epiphenomenon. A number of considerations make this simplified view seem unlikely. First, in healthy participants the ERN has been shown to be related to attempts to remediate the error (e.g., reflected in force reduction on errors and post-error slowing; Gehring et al., 1993), and reduced ERN-like activity on correct trials predicts the occurrence of errors (Allain, Carbonnell, Falkenstein, Burle, \& Vidal, 2004; Ridderinkhof, Nieuwenhuis, \& Bashore, 2003). Second, the absence of the ERN in patients does not necessarily mean that the generating structure does not show error-related activity. As elaborated above, desynchronized activity of neurons in the RCZ may result in reduced or even absent waveforms. The sustained midfrontal positivity beginning around $100 \mathrm{msec}$ after the error may hint at preserved neuronal activity in the frontomedian cortex. Thus, we propose that, in patients, the ERN is a sensitive indicator of the integrity of the performance monitoring network. Our findings as well as previous patient studies investigating focal brain lesions in relevant structures suggest that damage of one relay in this network seems to be accompanied by massive reduction of the ERP difference between errors and correct responses in the time window where the ERN would be expected (Stemmer, Segalowitz, Witzke, \& Schonle, 2004; Swick \& Turken, 2002; Ullsperger et al., 2002; Gehring \& Knight, 2000). It should be noted that the ERN is not impaired when lesions affect brain regions not directly involved in the frontostriatal performance monitoring network, such as frontopolar and temporal cortical lesions (Ullsperger et al., 2002). Why is this electrophysiological signature of impaired integrity of the performance monitoring network not accompanied by major behavioral deficits? Could ERPs be a more sensitive indicator of functional integrity than behavior? In the present study (as well as in previous studies), the lesions in the patients were chronic; at test, at least 1.5 years had elapsed since the damage occurred. Thus, time had been sufficient for the brain's plasticity to allow circumventing the damage functionally. This seems even more plausible, because lesions were unilateral and relatively small. Other brain regions may have taken over functionality to some extent and strategies may have changed. One should consider that these changes can compensate for behavioral deficits, but do not need to recover the electrophysiological correlates of error processing. Thus, behavioral deficits can be expected to be more apparent and persistent in patients with bilateral lesions of the performance monitoring network. A important question to be addressed in future research is whether more pronounced behavioral performance monitoring deficits are found in patients with acute lesions. Furthermore, the stability of the ERN impairment should be addressed in longitudinal studies encompassing acute and chronic lesion stages.

It could be assumed that the brain contains multiple error processing and correction systems that orchestrate optimal motor behavior. For example, the posterior parietal cortex has been implicated in the detection and correction of errors resulting from target perturbations in tracking tasks (Grea et al., 2002; Desmurget et al., 1999). It seems possible that the error correction in the flanker task may also depend on the posterior parietal cortex system for motor corrections, and that this system may largely compensate for deficits in the RCZ network.

In contrast to all other patients, three LPFC patients had strongly reduced error correction rates (P009, P102, P237), although showing similar ERP patterns as the other LPFC patients. Whereas all patients reported to have well recognized their errors in a postexperiment survey, one patient from the noncorrector subgroup (237) reported not to have recognized errors. The survey furthermore confirmed that all patients, including those impaired in error corrections, had understood and followed the task instructions, in particular the request to immediately correct errors. What is it that hampers the ability of these patients to correct errors? By a masking and overlaying procedure we extracted the lesion parts of the three noncorrectors that were unique to them compared to the four patients whose error correction abilities were normal. This part of the lesions is primarily located in the white matter at the base of the middle and inferior frontal gyri and the superior and anterior level of the external capsule system (Figure 1C). Based on the topography of this unique lesion part we suggest that fiber connections between the RCZ and the remaining intact parts of the LPFC as well as input from these regions to the striatum are disrupted. The data suggest these lesions in the frontal white matter get strategic relevance when they are combined with LPFC damage. Similarly as a direct lesion of the RCZ (Swick \& Turken, 2002), they lead to severe error correction impairments. Note that this lesion analysis cannot prove the role of the fiber connections between RCZ, LPFC, and BG, as the MR scans had to be normalized and aligned. However, it provides a strong hypothesis to be tested in future studies in patients with isolated white matter lesions in the relevant region.

In sum, the data provide strong support that the LPFC as well as prefrontal and motor cortico-striato-thalamocortical circuits are important for performance monitoring. The function of the RCZ seems to critically depend on its connectivity with the LPFC and the BG via the ventrolateral thalamus. Moreover, the ERN has proven to be a sensitive measure to assess the integrity of the entire network including its circuits, even in the absence 
of behavioral deficits. Large decrement or the absence of the ERN is an electrophysiological signature of impaired integrity of the performance monitoring system. However, ERN impairments do not need to map directly on behavioral deficits, as these different measures seem to be differentially susceptible to brain plasticity.

\section{Acknowledgments}

The authors thank T. Klein for help in data collection and M. Tittgemeyer and S. Seifert for support in lesion segmentation.

Reprint requests should be sent to Markus Ullsperger, Max Planck Institute for Human Cognitive and Brain Sciences, Stephanstrasse 1A, 04103 Leipzig, Germany, or via e-mail: ullsperg@cbs.mpg.de.

\section{Note}

1. Note that interactions of the Lateral dimension factor do not imply lateralization of the ERP; it can also be driven by an effect focused to midline electrodes.

\section{REFERENCES}

Alexander, G. E., Crutcher, M. D., \& DeLong, M. R. (1990). Basal ganglia-thalamocortical circuits: Parallel substrates for motor, oculomotor, "prefrontal" and "limbic" functions. Progress in Brain Research, 85, 119-146.

Allain, S., Carbonnell, L., Falkenstein, M., Burle, B., \& Vidal, F. (2004). The modulation of the Ne-like wave on correct responses foreshadows errors. Neuroscience Letters, 372, 161-166.

Barcelo, F., Suwazono, S., \& Knight, R. T. (2000). Prefrontal modulation of visual processing in humans. Nature Neuroscience, 3, 399-403.

Bar-Gad, I., Morris, G., \& Bergman, H. (2003). Information processing, dimensionality reduction and reinforcement learning in the basal ganglia. Progress in Neurobiology, 71, 439-473.

Bartholow, B. D., Pearson, M. A., Dickter, C. L., Sher, K. J., Fabiani, M., \& Gratton, G. (2005). Strategic control and medial frontal negativity: Beyond errors and response conflict. Psychophysiology, 42, 33-42.

Barto, A. G. (1995). Adaptive critics in the basal ganglia. In J. Houk, J. Davis, \& D. Beiser (Eds.), Models of information processing in the basal ganglia (pp. 215-232). Cambridge: MIT Press.

Bates, J. F., \& Goldman-Rakic, P. S. (1993). Prefrontal connections of medial motor areas in the rhesus monkey. Journal of Comparative Neurology, 336, 211-228.

Brass, M., \& von Cramon, D. Y. (2004). Decomposing components of task preparation with functional magnetic resonance imaging. Journal of Cognitive Neuroscience, 16, 609-620.

Coles, M. G., Scheffers, M. K., \& Holroyd, C. B. (2001). Why is there an ERN/Ne on correct trials? Response representations, stimulus-related components, and the theory of error-processing. Biological Psychology, 56, 173-189.

Dehaene, S., Posner, M. I., \& Tucker, D. M. (1994). Localization of a neural system for error detection and compensation. Psychological Science, 5, 303-305.

Derrfuss, J., Brass, M., \& von Cramon, D. Y. (2004). Cognitive control in the posterior frontolateral cortex: Evidence from common activations in task coordination, interference control, and working memory. Neuroimage, 23, 604-612.

Desmurget, M., Epstein, C. M., Turner, R. S., Prablanc, C., Alexander, G. E., \& Grafton, S. T. (1999). Role of the posterior parietal cortex in updating reaching movements to a visual target. Nature Neuroscience, 2, 563-567.

Dum, R. P., \& Strick, P. L. (1993). Cingulate motor areas. In B. A. Vogt \& M. Gabriel (Eds.), Neurobiology of cingulate cortex and limbic thalamus (pp. 415-441). Boston: Birkhäuser.

Falkenstein, M. (2004). ERP correlates of erroneous performance. In M. Ullsperger \& M. Falkenstein (Eds.), Errors, conflicts, and the brain. Current opinions on performance monitoring (pp. 5-14). Leipzig: MPI for Human Cognitive and Brain Sciences.

Falkenstein, M., Hielscher, H., Dziobek, I., Schwarzenau, P., Hoormann, J., Sunderman, B., \& Hohnsbein, J. (2001). Action monitoring, error detection, and the basal ganglia: An ERP study. NeuroReport, 12, 157-161.

Falkenstein, M., Hohnsbein, J., Hoormann, J., \& Blanke, L. (1990). Effects of errors in choice reaction tasks on the ERP under focused and divided attention. In C. H. M. Brunia, A. W. K. Gaillard, \& A. Kok (Eds.), Psychophysiological brain research (vol. 1, pp. 192-195). Tilburg, The Netherlands: Tilburg University Press.

Falkenstein, M., Hoormann, J., Christ, S., \& Hohnsbein, J. (2000). ERP components on reaction errors and their functional significance: A tutorial. Biological Psychology, 51, 87-107.

Fiehler, K., Ullsperger, M., \& von Cramon, D. Y. (2004). Neural correlates of error detection and error correction: Is there a common neuroanatomical substrate? European Journal of Neuroscience, 19, 3081-3087.

Fiehler, K., Ullsperger, M., \& Von Cramon, D. Y. (2005). Electrophysiological correlates of error correction. Psychophysiology, 42, 72-82.

Ford, J. M. (1999). Schizophrenia: The broken P300 and beyond. Psychophysiology, 36, 667-682.

Friederici, A. D., Kotz, S. A., Werheid, K., Hein, G., \& von Cramon, D. Y. (2003). Syntactic comprehension in parkinson's disease: Investigating early automatic and late integrational processes using event-related brain potentials Neuropsychology, 17, 133-142.

Frisch, S., Kotz, S. A., von Cramon, D. Y., \& Friederici, A. D. (2003). Why the P600 is not just a P300: The role of the basal ganglia. Clinical Neurophysiology, 114, 336-340.

Gehring, W. J., Goss, B., Coles, M. G., Meyer, D. E., \& Donchin, E. (1993). A neural system for error detection and compensation. Psychological Science, 4, 385-390.

Gehring, W. J., \& Knight, R. T. (2000). Prefrontal-cingulate interactions in action monitoring. Nature Neuroscience, 3, 516-520.

Gerfen, C. R. (1992). The neostriatal mosaic: Multiple levels of compartmental organization in the basal ganglia. Annual Review of Neuroscience, 15, 285-320.

Gillies, A., \& Arbuthnott, G. (2000). Computational models of the basal ganglia. Movement Disorders, 15, 762-770.

Gratton, G., Coles, M. G., \& Donchin, E. (1983). A new method for off-line removal of ocular artifact. Electroencephalography and Clinical Neurophysiology, 55, 468-484.

Graybiel, A. M., Aosaki, T., Flaherty, A. W., \& Kimura, M. (1994). The basal ganglia and adaptive motor control. Science, 265, 1826-1831.

Grea, H., Pisella, L., Rossetti, Y., Desmurget, M., Tilikete, C., Grafton, S., Prablanc, C., \& Vighetto, A. (2002). A lesion of the posterior parietal cortex disrupts on-line adjustments during aiming movements. Neuropsychologia, 40, 2471-2480. 
Haber, S. N. (2003). The primate basal ganglia: Parallel and integrative networks. Journal of Chemical Neuroanatomy, 26, 317-330.

Hatanaka, N., Tokuno, H., Hamada, I., Inase, M., Ito, Y., Imanishi, M., Hasegawa, N., Akazawa, T., Nambu, A., \& Takada, M. (2003). Thalamocortical and intracortical connections of monkey cingulate motor areas. Journal of Comparative Neurology, 462, 121-138.

Holroyd, C. B., \& Coles, M. G. (2002). The neural basis of human error processing: Reinforcement learning, dopamine, and the error-related negativity. Psychological Review, 109, 679-709.

Holroyd, C. B., Praamstra, P., Plat, E., \& Coles, M. G. (2002). Spared error-related potentials in mild to moderate parkinson's disease. Neuropsychologia, 40, 2116-2124.

Houk, J. C., Adams, J. L., \& Barto, A. G. (1995). A model of how the basal ganglia generate and use neural signals that predict reinforcement. In J. C. Houk, J. Davis, \& D. Beiser (Eds.), Models of information processing in the basal ganglia (pp. 249-270). Cambridge: MIT Press.

Huynh, H., \& Feld, L. S. (1970). Conditions under which mean square ratios in repeated measurements designs have exact F distributions. Journal of the American Statistical Association, 65, 1582-1589.

Knight, R. T., \& Scabini, D. (1998). Anatomic bases of eventrelated potentials and their relationship to novelty detection in humans. Journal of Clinical Neurophysiology, 15, 3-13.

Koski, L., \& Paus, T. (2000). Functional connectivity of the anterior cingulate cortex within the human frontal lobe: A brain-mapping meta-analysis. Experimental Brain Research, $133,55-65$.

MacDonald, A. W., III, Cohen, J. D., Stenger, V. A., \& Carter, C. S. (2000). Dissociating the role of the dorsolateral prefrontal and anterior cingulate cortex in cognitive control. Science, 288, 1835-1838.

Nieuwenhuis, S., Ridderinkhof, K. R., Blom, J., Band, G. P., \& Kok, A. (2001). Error-related brain potentials are differentially related to awareness of response errors: Evidence from an antisaccade task. Psychophysiology, 38, 752-760.

O’Doherty, J., Dayan, P., Schultz, J., Deichmann, R., Friston, K., \& Dolan, R. J. (2004). Dissociable roles of ventral and dorsal striatum in instrumental conditioning. Science, 304, 452-454.

Paus, T., Castro-Alamancos, M. A., \& Petrides, M. (2001). Cortico-cortical connectivity of the human mid-dorsolateral frontal cortex and its modulation by repetitive transcranial magnetic stimulation. European Journal of Neuroscience, 14, 1405-1411.

Petrides, M., \& Pandya, D. N. (1999). Dorsolateral prefrontal cortex: Comparative cytoarchitectonic analysis in the human and the macaque brain and corticocortical connection patterns. European Journal of Neuroscience, 11, 1011-1036.

Rabbitt, P. (2002). Consciousness is slower than you think. Quarterly Journal of Experimental Psychology, A, 55, 1081-1092.

Ridderinkhof, K. R., Nieuwenhuis, S., \& Bashore, T. R. (2003). Errors are foreshadowed in brain potentials associated with action monitoring in cingulate cortex in humans.

Neuroscience Letters, 348, 1-4.

Ridderinkhof, K. R., Ullsperger, M., Crone, E. A., \&

Nieuwenhuis, S. (2004). The role of the medial frontal cortex in cognitive control. Science, 306, 443-447.

Rorden, C., \& Karnath, H. O. (2004). Using human brain lesions to infer function: A relic from a past era in the fMRI age? Nature Reviews Neuroscience, 5, 813-819.

Schultz, W. (2002). Getting formal with dopamine and reward. Neuron, 36, 241-263.

Stemmer, B., Segalowitz, S. J., Witzke, W., \& Schonle, P. W. (2004). Error detection in patients with lesions to the medial prefrontal cortex: An ERP study. Neuropsychologia, 42, 118-130.

Stemmer, B., \& Witzke, W. (2003). The effects of brain damage on the error negativity (Ne/ERN). Paper presented at the Errors, Conflicts, and The Brain. Current Opinions on Performance Monitoring Conference, Dortmund, Germany.

Swick, D., \& Turken, A. U. (2002). Dissociation between conflict detection and error monitoring in the human anterior cingulate cortex. Proceedings of the National Academy of Sciences, U.S.A., 99, 16354-16359.

Takada, M., Tokuno, H., Hamada, I., Inase, M., Ito, Y., Imanishi, M., Hasegawa, N., Akazawa, T., Hatanaka, N., \& Nambu, A. (2001). Organization of inputs from cingulate motor areas to basal ganglia in macaque monkey. European Journal of Neuroscience, 14, 1633-1650.

Talairach, P., \& Tournoux, J. (1988). A stereotactic coplanar atlas of the buman brain. Stuttgart: Thieme.

Ullsperger, M., Volz, K. G., \& von Cramon, D. Y. (2004). A common neural system signaling the need for behavioral changes. Trends in Cognitive Sciences, 8, 445-446.

Ullsperger, M., \& von Cramon, D. Y. (2001). Subprocesses of performance monitoring: A dissociation of error processing and response competition revealed by event-related fMRI and ERPs. Neuroimage, 14, 1387-1401.

Ullsperger, M., \& von Cramon, D. Y. (2004). Neuroimaging of performance monitoring: Error detection and beyond. Cortex, 40, 593-604.

Ullsperger, M., von Cramon, D. Y., \& Müller, N. G. (2002). Interactions of focal cortical lesions with error processing: Evidence from event-related brain potentials. Neuropsychology, 16, 548-561.

van Veen, V., \& Carter, C. S. (2002). The timing of actionmonitoring processes in the anterior cingulate cortex. Journal of Cognitive Neuroscience, 14, 593-602.

Vidal, F., Burle, B., Bonnet, M., Grapperon, J., \& Hasbroucq, T. (2003). Error negativity on correct trials: A reexamination of available data. Biological Psychology, 64, 265-282.

Williams, Z. M., Bush, G., Rauch, S. L., Cosgrove, G. R., \& Eskandar, E. N. (2004). Human anterior cingulate neurons and the integration of monetary reward with motor responses. Nature Neuroscience, 7, 1370-1375.

Yamaguchi, S., \& Knight, R. T. (1991). Anterior and posterior association cortex contributions to the somatosensory P300. Journal of Neuroscience, 11, 2039-2054.

Yeung, N., Cohen, J. D., \& Botvinick, M. M. (2004). The neural basis of error detection: Conflict monitoring and the error-related negativity. Psychological Review, 111, 931-959. 